University of Wollongong

Research Online

Faculty of Engineering and Information

Faculty of Engineering and Information

Sciences - Papers: Part B

Sciences

2019

Residual capacity of cold-formed steel rack uprights following stomping during rocking

James Maguire

University of Wollongong, jrm978@uowmail.edu.au

Lip H. Teh

University of Wollongong, Iteh@uow.edu.au

G Charles Clifton

University of Auckland

James Lim

University of Auckland

Follow this and additional works at: https://ro.uow.edu.au/eispapers1

Part of the Engineering Commons, and the Science and Technology Studies Commons

Research Online is the open access institutional repository for the University of Wollongong. For further information contact the UOW Library: research-pubs@uow.edu.au 


\title{
Residual capacity of cold-formed steel rack uprights following stomping during rocking
}

\author{
Abstract \\ When selective pallet racks are allowed to rock in the cross-aisle direction during an earthquake, the \\ uprights are subjected to short duration high axial forces at stomping. In this paper, the amplitude of the \\ stomping force needed to compromise the upright's residual capacity is assessed for 59 configurations \\ using nonlinear inelastic static and dynamic analyses. Parametric studies are performed to investigate \\ the effects of upright length, bracing pitch, section slenderness, torsional restraints and multiple impulses \\ on the residual capacity of an upright due to rocking. Uprights that fail in the flexural-torsional buckling \\ mode perform better than those that fail by local-distortional buckling as the stomping causes permanent \\ local-distortional deformations rather than sweep (torsional deformation). A rack upright that has a \\ greater length, greater thickness and lower torsional restraint tends to have a higher residual capacity \\ (relative to the undamaged capacity). A typical cold-formed steel rack upright can sustain a $0.1 \mathrm{~s}$ \\ stomping force that is at least $15 \%$ greater than its static ultimate capacity without significant reduction \\ in residual capacity. An implication is that an unanchored upright that survives an earthquake through \\ rocking may double its storage load during the post-earthquake emergency period. The present shell \\ element analysis results can be used to plan an experimental program for optimising the resilience of \\ storage rack uprights against stomping.

\section{Disciplines \\ Engineering | Science and Technology Studies}

\section{Publication Details} \\ Maguire, J. R., Teh, L. H., Clifton, G. Charles. \& Lim, J. B. P. (2019). Residual capacity of cold-formed steel \\ rack uprights following stomping during rocking. Journal of Constructional Steel Research, 159 189-197.
}


Keywords: cold-formed steel upright; earthquake recovery; residual capacity; rocking;

\section{Residual capacity of cold-formed steel rack uprights following stomping during rocking}

\author{
James R. Maguire ${ }^{\mathrm{a}}$, Lip H. Teh ${ }^{\mathrm{a}}$, G. Charles Clifton ${ }^{\mathrm{b}}$, James B.P. Lim ${ }^{\mathrm{b}}$ \\ ${ }^{a}$ School of Civil, Mining \& Environmental Engineering, University of Wollongong, Wollongong, NSW 2522, \\ Australia. \\ ${ }^{\mathrm{b}}$ Department of Civil and Environmental Engineering, University of Auckland, Auckland, New Zealand. \\ *Corresponding author, e-mail: 1teh@uow.edu.au
}

\section{Abstract}

When selective pallet racks are allowed to rock in the cross-aisle direction during an earthquake, the uprights are subjected to short duration high axial forces at stomping. In this paper, the amplitude of the stomping force needed to compromise the upright's residual capacity is assessed for 59 configurations using nonlinear inelastic static and dynamic analyses. Parametric studies are performed to investigate the effects of upright length, bracing pitch, section slenderness, torsional restraints and multiple impulses on the residual capacity of an upright due to rocking. Uprights that fail in the flexural-torsional buckling mode perform better than those that fail by local-distortional buckling as the stomping causes permanent local-distortional deformations rather than sweep (torsional deformation). A rack upright that has a greater length, greater thickness and lower torsional restraint tends to have a higher residual capacity (relative to the undamaged capacity). A typical cold-formed steel rack upright can sustain a $0.1 \mathrm{~s}$ stomping force that is at least $15 \%$ greater than its static ultimate capacity without significant reduction in residual capacity. An implication is that an unanchored upright that survives an earthquake through rocking may double its storage load during the post-earthquake emergency period. The present shell element analysis results can be used to plan an experimental program for optimising the resilience of storage rack uprights against stomping. stomping 
Cold-formed steel pallet racking structures are used to hold goods in storage and distribution warehouses worldwide. For storage of mixed SKUs (stock keeping units), a selective pallet racking system will often be used, allowing direct access to individual pallets by forklift or reach truck. A selective pallet rack system is shown in Figure 1.

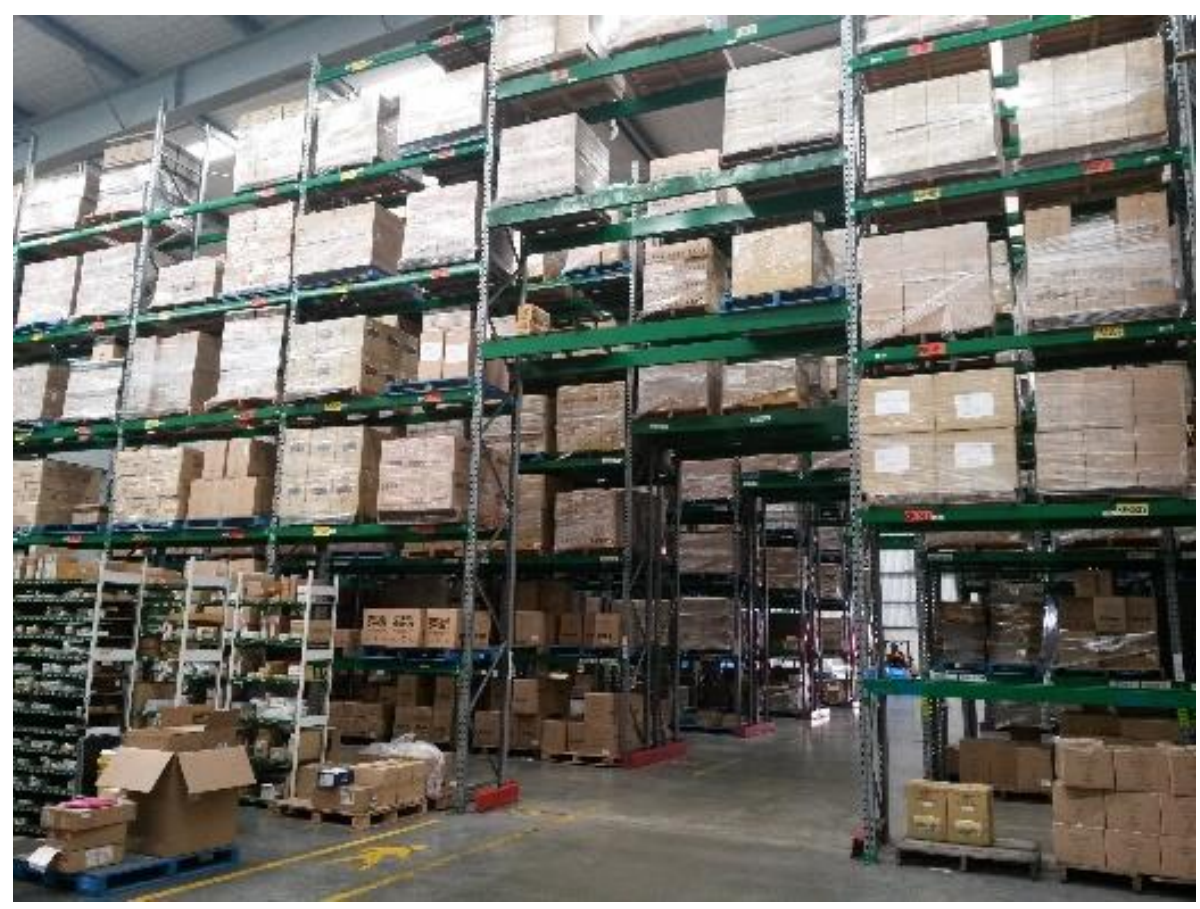

Figure 1: Loaded selective pallet racking in distribution warehouse (Maguire 2019)

Selective racks are designed to resist gravity loading using modular systems of uprights, bracings, and beams. The upright and bracing members are arranged into upright frames that resist lateral loads in the cross-aisle direction. These upright frames are connected together with an array of beams, forming a semi-rigid frame in the down-aisle direction.

There are two mechanisms by which selective racks resist overturning due to cross-aisle lateral loading. First, the pallet live load provides a restoring moment for small displacements. Secondly, the rack baseplates, connecting the upright base to the floor, transfer uplifting forces through to the foundation. The conventional rack baseplate consists of a stub connected to the base of the upright, and welded to a floor-plate which is anchored to the concrete foundation, as shown in Figure 2. In seismic regions, it is desirable for the baseplate to have a low stiffness to increase the structural period and protect the foundation from high uplift forces. Low stiffness baseplates allow the rack to uplift under cross-aisle lateral loading, leading to rocking motion during an earthquake (Maguire et al. 2018a). 


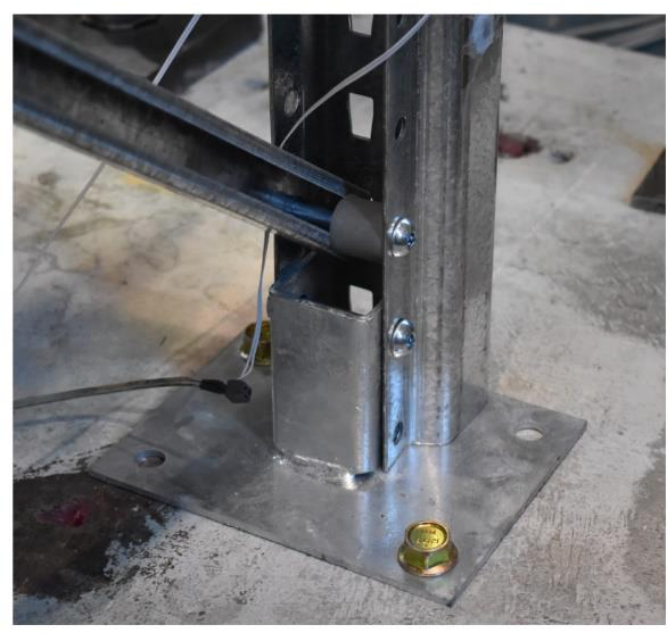

(a)

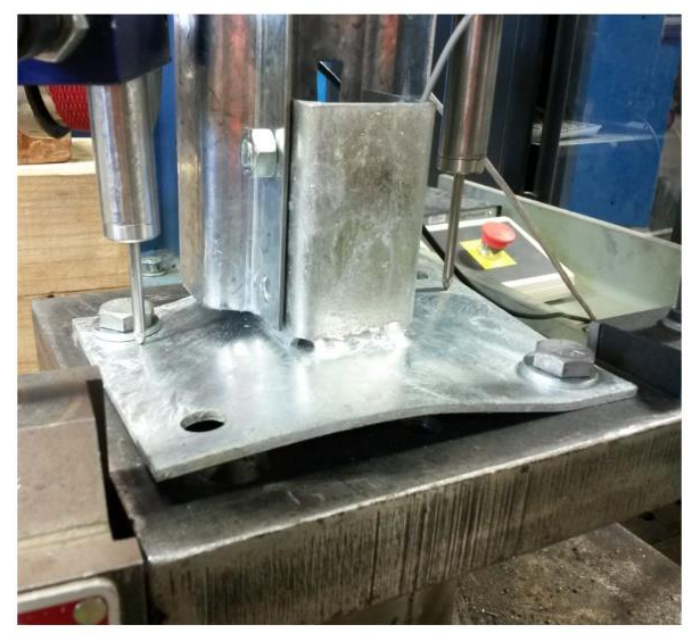

(b)

Figure 2: Ductile baseplate connecting 90-20-L upright to concrete foundation: (a) Undeformed; (b)

Deformed due to uplifting.

Rocking has been found to improve the seismic performance of a number of structures, such as bridge piers, shear walls, and self-centring steel frames. Allowing structures to rock can reduce internal forces, permanent deformations and base shear. It has even been found in some cases to decrease the likelihood of overturning (Makris and Zhang 1999). A challenge in the design of rocking structures, however, is managing the dynamic compression forces which arise from stomping. Stomping refers to the impulse action of an upright (or column) of a rocking structure as it comes down to the ground periodically, alternating with uplifting.

Rocking can amplify axial forces of the uprights when the uplifted side of the structure drops and impacts with the foundation (Priestley et al. 1978; Azuhata et al. 2007). For such a short duration of peak loading, it is of interest to determine the magnitude of impulse that will cause damage leading to a significant reduction in the member's static ultimate capacity.

Literature on the behaviour of steel members subjected to high strain rates is available in the fields of blast impact, but the impact load is typically applied laterally to the member although high strain rate axial loading of steel tubes has been investigated during crushing for applications in the automotive industry (Mamalis et al. 1984). These studies are concerned with the energy absorption of the material rather than the member's ability to maintain its static ultimate capacity after impulse loading. At the time of writing, literature on the effect of axial impulse loads in the order of the member's static ultimate capacity has not been found.

During impulse loading, it is important to consider the effects of strain rate on the member's material properties. At a very high rate of loading, the mechanical properties of cold-formed 
steel are substantially changed. The yield stress increases with strain rate, leading to increased importance of local buckling due to an increase in cross-section slenderness (Chen and Liew 2005). For impact design, the increase in yield stress is characterised by a dynamic increase factor $D I F_{y} \geq 1.0$. High strain rates also increase the ultimate tensile strength, but have no effect on the modulus of elasticity (Gilsanz et al. 2013).

The dynamic increase factors for the yield stress and the ultimate strength of Grade 350 reinforcing steel bars at a strain rate of $\dot{\varepsilon}=0.01 / \mathrm{s}$ are $D I F_{y}=1.18$ and $D I F_{u}=1.06$, respectively (DOD 2008). For A36 and A572 grade structural steels (with a measured yield stress of $345 \mathrm{MPa}$ ) at a strain rate of $0.1 / \mathrm{s}$, the values of $D I F_{y}$ are in the range 1.10-1.12 and those of $D I F_{u}$ are between 1.00 and 1.05 (Gilsanz et al. 2013). The DIF 's for tension coupons cut from rectangular hollow sections with a thickness of $3 \mathrm{~mm}$ and yield stresses between $450 \mathrm{MPa}$ and $550 \mathrm{MPa}$ were consistently greater than 1.1 for strain rates in the order of $0.1 / \mathrm{s}$ (Ritchie et al. 2017a).

The magnitude of the stomping load on a steel frame can be controlled using friction damping devices at the rocking joint (Wiebe et al. 2013), but the increase in cost may not be suitable for the competitive pallet racking industry. If the uprights can be shown to sustain short duration axial impulses with amplitudes significantly greater than their static ultimate capacity, lighter members can be used for projects where stomping forces govern the design. Information on the attributes of an upright that increase its resilience against stomping forces during strong earthquake will also be useful.

This paper aims to assess the magnitudes of stomping forces that can be sustained by typical cold-formed steel rack uprights without significant reductions in their residual capacities. Parametric finite element studies have been conducted to investigate the effects of upright length, bracing pitch, section slenderness and torsional restraint on its resilience against stomping forces during earthquake (rocking). The analysis results can also help devise an experimental program for optimising the resilience of a storage rack that rocks during earthquake, to provide more comprehensive experimental verification to that obtained through the shake table testing (Maguire 2019). 
98 applied in the cross-aisle direction, resulting in rocking of the upright frames.

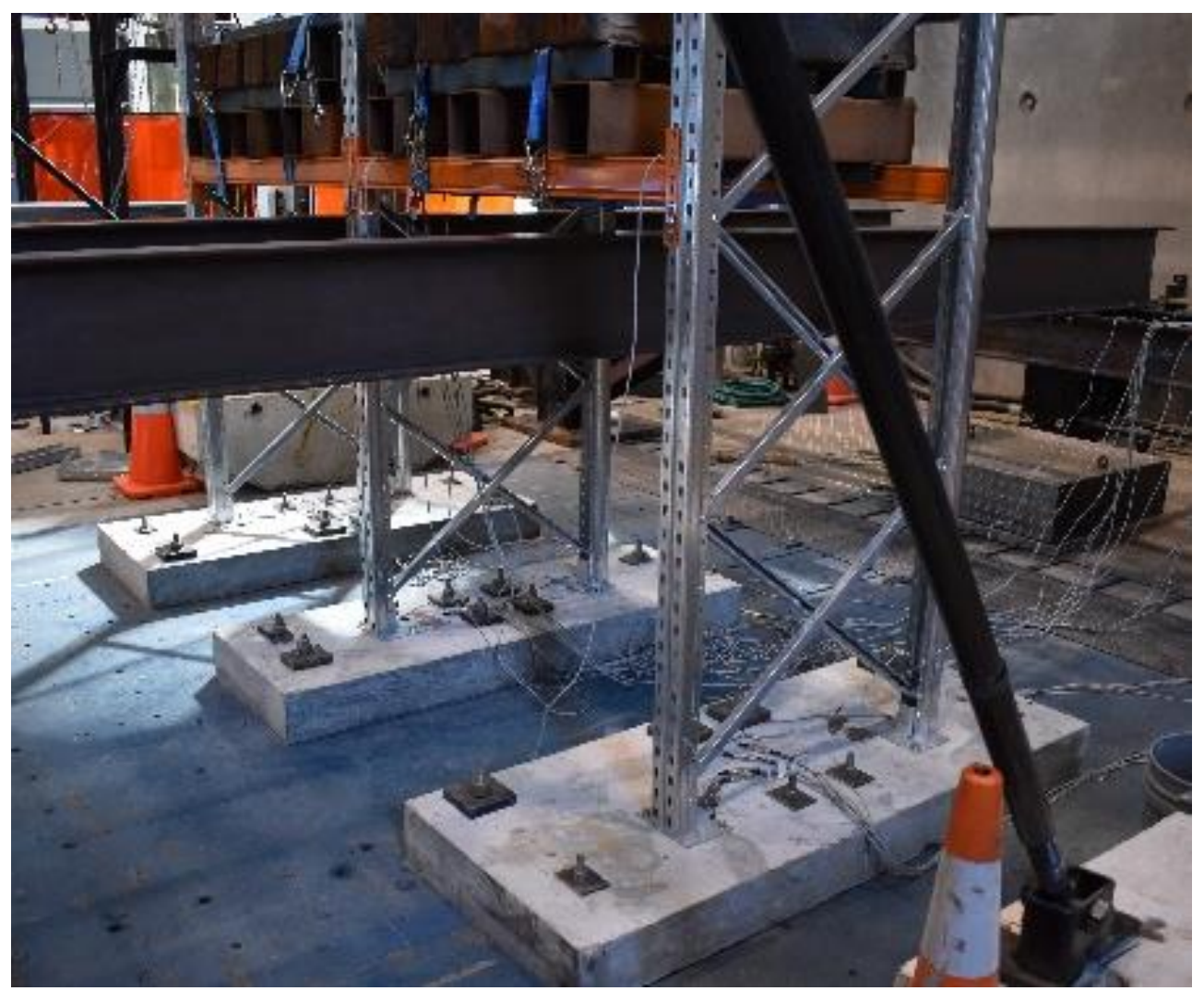

Figure 3: Shaking table test of selective pallet rack in the cross-aisle direction

106 The axial loads of the uprights during the shaking table tests were recorded indirectly using two

107 single axis strain gauges per upright. The 90-20-L upright cross-section (see Figure 4(a)) was 108 used, with the strain gauges installed in line with the neutral axis on the flange outer wall and $109200 \mathrm{~mm}$ from the base. The strain data sample rate was $100 \mathrm{~Hz}$. It was found that the peak axial 
110 loads occurred as (short duration) impulses. The impulses typically had a duration around $0.1 \mathrm{~s}$ 111 and could be approximated by a half sine wave, as evident from Figure 5.

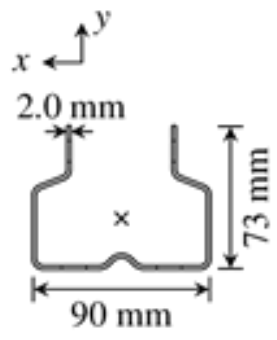

(a) $90-20-\mathrm{L}$

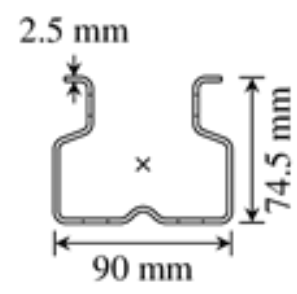

(b) $90-25-\mathrm{H}$

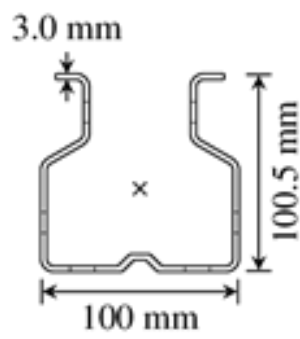

(c) $100-30-\mathrm{H}$

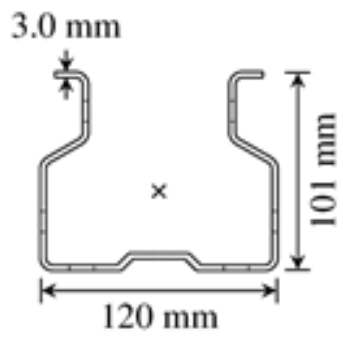

(d) $120-30-\mathrm{H}$

Figure 4: Upright cross-sections

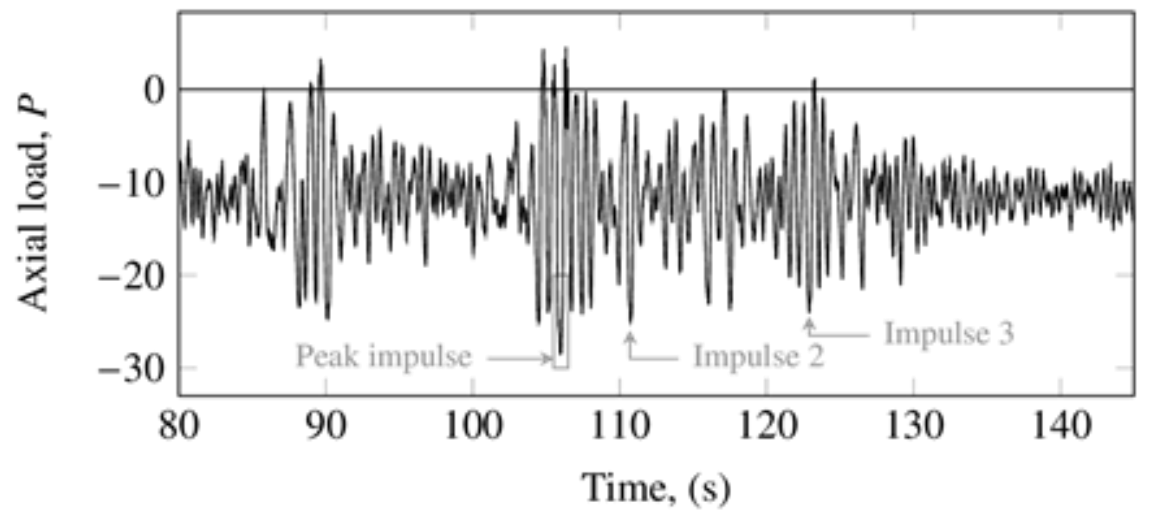

Figure 5: Axial loads of rack upright subjected to Kaikoura 2016 ground motion in the cross-aisle

direction

116 Table 1 shows the three largest relevant stomping forces experienced by the uprights, during 117 each of the authors' shaking table tests, as ratios of the respective largest stomping forces. The 118 first ratio, which is unity, refers to the largest stomping force. The second and third ratios correspond to the next largest stomping forces after the largest one, as any damage in the form

120 of inelastic deformations would be added after the largest stomping force. The three relevant 121 stomping forces for the Kaikoura earthquake are indicated in Figure 5. However, for the Kobe 122 ground motion the maximum peak occurred close to the end of the shaking duration, so the 123 second and third largest forces shown in the table for the present study occurred before the peak.

124 In any case, it can be seen that the second and third largest stomping forces never exceeded $12575 \%$ of the largest stomping force for each ground motion tested. This information is used in Sections 3.5 and 4.8 . 
128 Table 1: The three largest axial loads recorded for each ground motion as ratios of the peak load

\begin{tabular}{lccc}
\hline & \multicolumn{3}{c}{ Impulse } \\
\cline { 2 - 4 } Ground motion & 1 & 2 & 3 \\
\hline Kaikoura & 1.00 & 0.71 & 0.70 \\
Kobe & 0.75 & 0.73 & 1.00 \\
Northridge & 1.00 & 0.60 & 0.59 \\
\hline
\end{tabular}

\section{Upright models}

\section{$130 \quad 3.1$ Cross-sections and boundary conditions}

131 Four different upright sections, based on the existing ones used in the pallet rack industry, were 132 considered, as shown in Figure 4. The first number in each section name indicates the web depth 133 in millimetres, the second the wall thickness, and the letter indicates whether it has a rear flange 134 stiffener $(\mathrm{H})$ or not $(\mathrm{L})$. All sections had slotted web perforations for hooked beam-end 135 connectors and circular rear flange perforations for bolted bracing connections, as illustrated in 136 Figure 6. Perforations were spaced at $50 \mathrm{~mm}$ for the whole length of the upright. The 100-30$137 \mathrm{H}$ and 120-30-H uprights had circular flange perforations in addition to the rear flange 138 perforations, as shown in Figure 6(b).

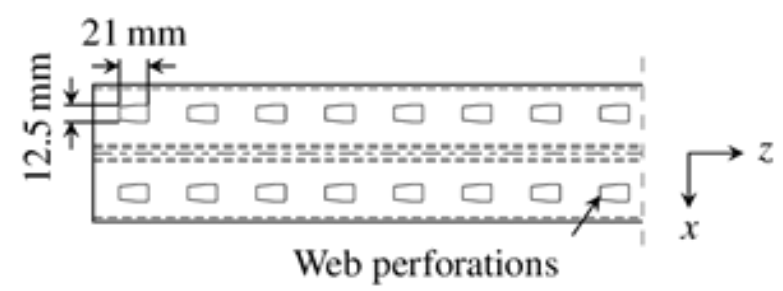

(a)

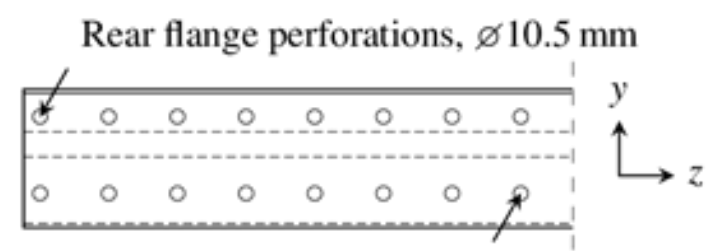

Flange perforations, $\varnothing 10.5 \mathrm{~mm}$

(b)

Figure 6: Perforations on the 100-30-H upright

140 The upright members were modelled using S4R shell elements (ABAQUS 2014). All element 141 edges at the top and bottom of the upright were constrained to a reference point at the cross142 section neutral axis with multi-point constraint (MPC) beam constraints, as shown in Figure 7.

143 The top reference point was restrained for all translational degrees of freedom (DOF) and the $144 r Z$-DOF. The $X, Y$ and $r Z$ degrees of freedom for the bottom reference point were restrained, 145 and the compressive axial load $P$ was applied to the $Z$-DOF. Each upright was therefore simply 146 supported. 


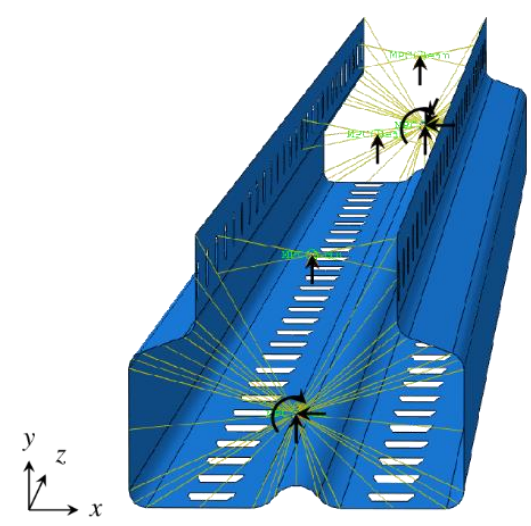

148 The upright was considered to be part of an upright frame with a X-bracing pattern, as illustrated

149 in Figure 8. Braces were connected at the rear flange perforations of the uprights with a uniform

150 pitch of $600 \mathrm{~mm}$. The element edges on both rear flanges were tied to a reference point at the

151 centreline of the cross-section, which was restrained in the $Y$-DOF to simulate the restraint 152 provided by the bracing.

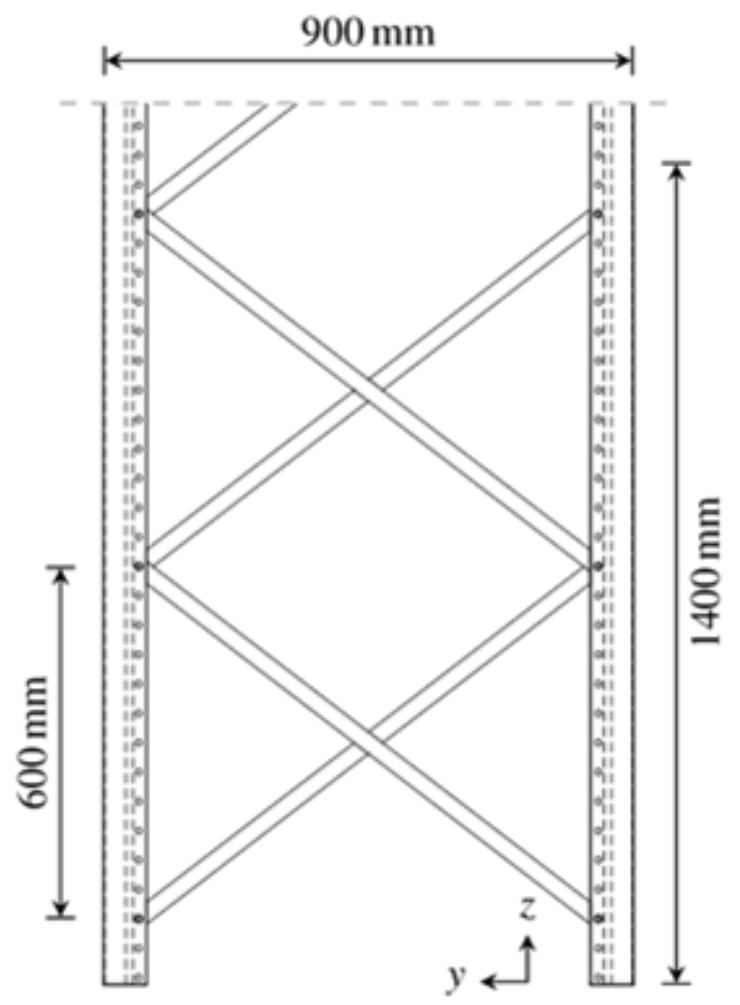

Figure 8: Upright frame with X-bracing pattern 
155 A bilinear steel material with rate dependency was applied to all elements. The modulus of 156 elasticity was set to $E=200 \mathrm{GPa}$, the yield stress $f_{y}=450 \mathrm{MPa}$, and the ultimate strength $f_{u}=$ $157480 \mathrm{MPa}$. These nominal properties correspond to G450 sheet steel (SA 2011) commonly used 158 for cold-formed steel rack uprights in Australia. The plasticity of the steel material was handled

159 through the von Mises yield criterion and the Prandtl-Reuss flow rule with isotropic hardening.

160 A dynamic increase factor for the yield stress of $D I F_{y}=1.1$ was applied at a loading rate of 1610.4 /s based on the results compiled by Ritchie et al. (2017b). The yield stress as a function of 162 strain rate is interpolated using the Cowper-Symonds overstress power law (Cowper and 163 Symonds 1957).

\subsection{Mesh refinement}

165 Appropriate mesh sizes for the upright models were determined by a series of linear buckling 166 analyses with varying mesh sizes. Using approximately square quadrilateral shell elements of 167 mesh sizes larger than $4 \mathrm{~mm}$, it was found that the elastic buckling eigenvalues were 168 significantly lower than expected. The low eigenvalues were due to a reduction in stiffness 169 caused by the lack of detail of the rounded corners, which were reduced to a single element. It 170 was found that only when the rounded corners were modelled with mesh sizes equal to or 171 smaller than $1 \mathrm{~mm}$, the eigenvalues converged to the expected value.

172 The final mesh used for the upright models is shown in Figure 9. The mesh was generated using 173 approximate mesh sizes of $1 \mathrm{~mm}$ for rounded edges, $3 \mathrm{~mm}$ for flange and rear flange edges with 174 circular perforations, $5 \mathrm{~mm}$ for web edges with slotted perforations, and $10 \mathrm{~mm}$ for flat edges 175 with no perforations along the length of the upright. The longitudinal mesh approximate size 176 was $10 \mathrm{~mm}$. 


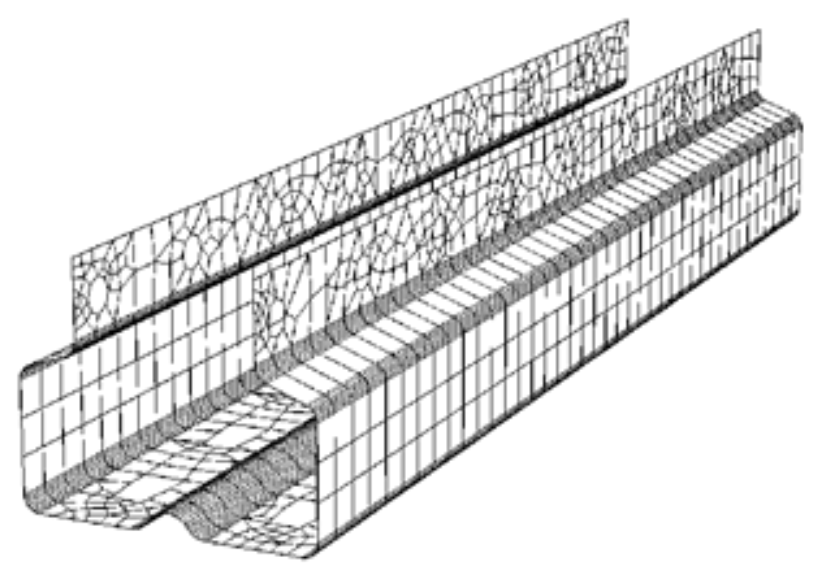

\subsection{Model validation}

179 To validate the finite element modelling methodology, the upright compression test results

180 obtained by Koen (2008) were used for verification. Interested readers may find details of the 181 geometry and material properties by downloading the reference from

182 https://ses.library.usyd.edu.au/handle/2123/3880.

183 The three nominally identical specimens tested by Koen (2008) had an average static ultimate 184 capacity of $268 \mathrm{kN}$, which was closely matched by the ultimate limit load of $266 \mathrm{kN}$ found by 185 the present finite element model. The failure mode of the finite element model also resembles 186 that of the tested uprights, as evident in Figure 10.

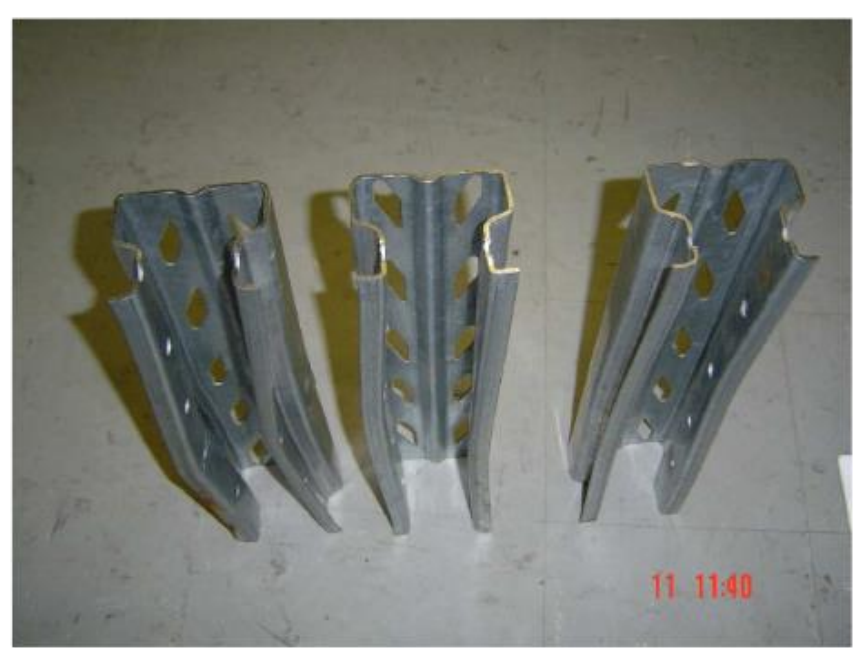

(a) Upright stubs after testing (Koen, 2008)

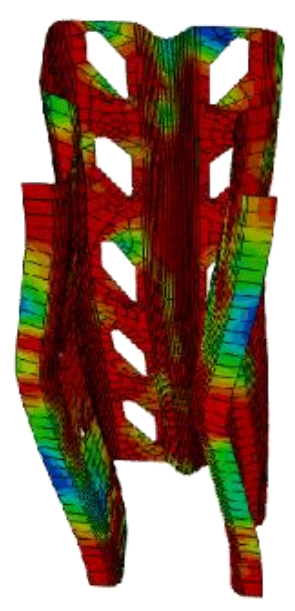

(b) FEA model

Figure 10: Validation of model against upright stub compression tests 
189 The parameters investigated in the present work are the upright length, bracing pitch, section 190 slenderness and torsional restraint. The reference value of each parameter was: length = $1911400 \mathrm{~mm}$; bracing pitch $=600 \mathrm{~mm}$; section thickness as given in Figure 4; cross-section scale $192=100 \%$. These values can be assumed for all upright models unless indicated otherwise.

193 Four upright lengths were considered for each section, being $1000 \mathrm{~mm}, 1400 \mathrm{~mm}, 1700 \mathrm{~mm}$ 194 and $2000 \mathrm{~mm}$. As mentioned in Section 3.1 and indicated in Figure 11, the bracing points are 195 restrained translationally in the cross-aisle direction.

196

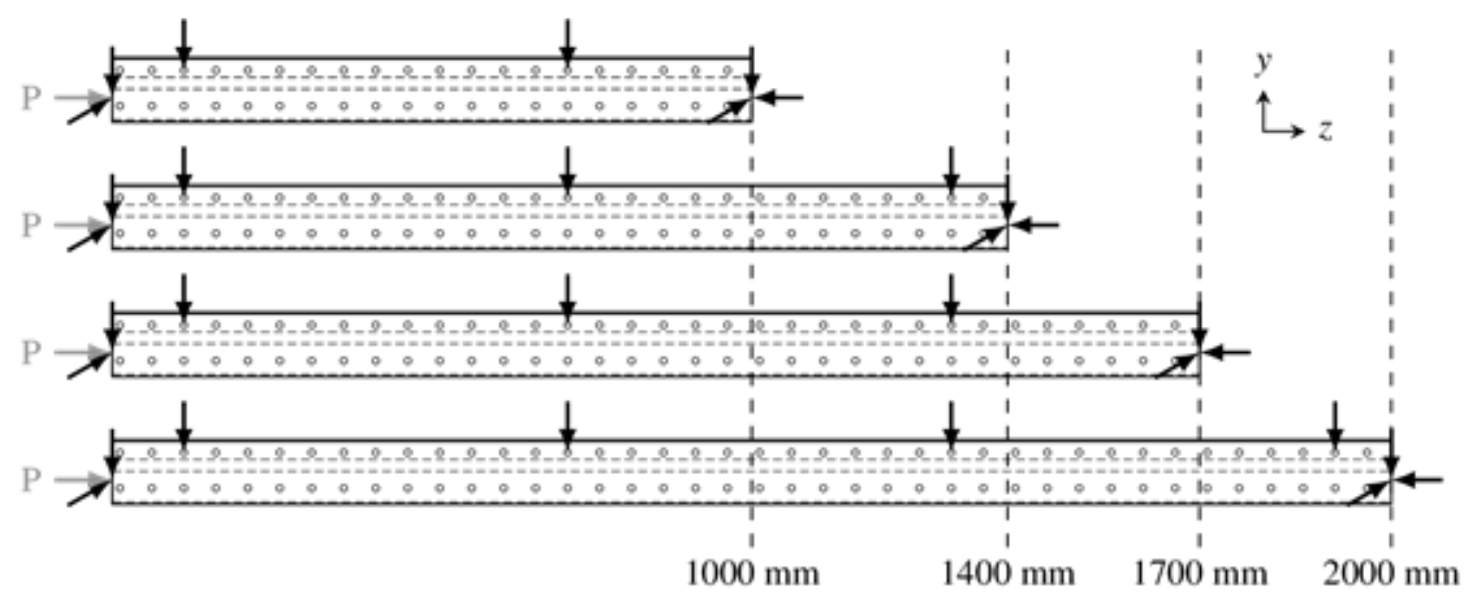

Figure 11: Lengths and translational boundary conditions of uprights with X-brace configuration

198

The reference value of bracing pitch, which is $600 \mathrm{~mm}$, is typical for an X-brace configuration used for cold-formed steel pallet racks in seismic zones. During earthquake, X-bracing at the lower end of an upright frame reduces the bending moment about the upright's weak axis caused by base shear. However, the K-bracing configuration was also considered in the present study. The pitch of a K-braced upright frame is double that of an X-braced one, being $1200 \mathrm{~mm}$.

Four section thicknesses were considered for the 90-?-H, 100-?-H and 120-?-H uprights, being $2.0 \mathrm{~mm}, 2.5 \mathrm{~mm}, 3.0 \mathrm{~mm}$ and $3.5 \mathrm{~mm}$. For the 90-?-L upright, only the first three thicknesses were included.

Four cross-section scaling factors were tested for the $1400 \mathrm{~mm} \mathrm{100-30-H} \mathrm{upright,} \mathrm{being} \mathrm{90 \% ,}$ $100 \%, 110 \%$, and 120\%. All cross-section dimensions, including thickness, were scaled uniformly, but the perforation dimensions remained at $100 \%$. 
Unless otherwise noted, each model was subjected to a single impulse in each analysis to

210 determine the residual capacity of the upright, as described in the next section. However, for 211 the purpose of investigating the effects of multiple impulses during rocking of the upright 212 frame, two series of multiple impulses were analysed, each of which involving three 213 consecutive impulses. In the first series, each upright was subjected to three consecutive 214 impulses of equal amplitude. In the second series, it was subjected to three consecutive impulses 215 with the second and third impulses at $75 \%$ of the first amplitude. The latter analysis is more 216 realistic as indicated previously in Section 2.

\section{$217 \quad 3.6 \quad$ Loading condition, imperfections and residual capacity}

218 A rack upright is subjected to the maximum compression (and stomping force) when the two 219 adjacent bays are fully loaded, in which case the typical upright is not subjected to bending moment in the down-aisle direction prior to the earthquake due to symmetric loading of the beams. For the purpose of the present work, the upright is assumed to be subjected to axial stomping forces only. However, initial imperfections corresponding to the first member and cross-section buckling modes are included in the nonlinear static and dynamic analyses as described in the next section. The application of the stomping force may also result in permanent damage in the form of inelastic cross-section and/or member deformations, which reduce the residual capacity.

It is assumed that the reduction of an upright's capacity under combined compression and bending is proportional to that under compression only, the latter being investigated in the present work.

\section{Analysis and results}

\subsection{Analysis procedure}

232 The residual capacity $P_{u r}$ of an upright member is defined as the static ultimate capacity of the 233 damaged member following the application of an impulse (or impulses). The residual capacity 234 for each upright member was determined using the following procedure:

1. Linear buckling analyses are performed to determine the lowest member and cross-section buckling modes, which are then superimposed onto the perfect member geometry as initial imperfections after being scaled by $\delta_{o}=L / 1000$ and $s_{o}=0.3 t \sqrt{f_{y} / f_{o}}$ respectively, as 
specified by AS 4084 (Standards Australia 2012). The upright model with initial imperfections is referred to hereafter as the undamaged upright.

2. The static ultimate capacity of the undamaged upright $P_{u}$ is determined by geometric and material nonlinear analysis using the arc length method (Riks 1979) in Abaqus/Standard (ABAQUS 2014). The static ultimate capacity for each upright member is provided in Table 2.

3. An axial impulse is applied to the undamaged upright, analysed in Abaqus/Explicit (ABAQUS 2014). The impulse is in the form of a half-sine pulse of duration $0.1 \mathrm{~s}$ and amplitude $P_{A}$ followed by a $2.9 \mathrm{~s}$ rest period of zero load, as shown in Figure 12 .

4. The residual capacity $P_{u r}$ (static ultimate capacity of the damaged upright) is determined Determination of the analyses duration is explained in Section 4.2. The inelastic nodal by geometric and material nonlinear analysis of the damaged upright model using the arc length method (Riks 1979).

254 Table 2: Static ultimate capacity $P_{u}$ of upright members

\begin{tabular}{ccccc}
\hline & \multicolumn{4}{c}{ Static ultimate capacity $P_{u}(\mathrm{kN})$} \\
\cline { 2 - 5 } Length $(\mathrm{mm})$ & $90-20-\mathrm{L}$ & $90-25-\mathrm{H}$ & $100-30-\mathrm{H}$ & $120-30-\mathrm{H}$ \\
\hline 1000 & 160 & 247 & 350 & 379 \\
1400 & 148 & 219 & 332 & 367 \\
1700 & 145 & 198 & 307 & 359 \\
2000 & 130 & 168 & 274 & 333 \\
\hline
\end{tabular}

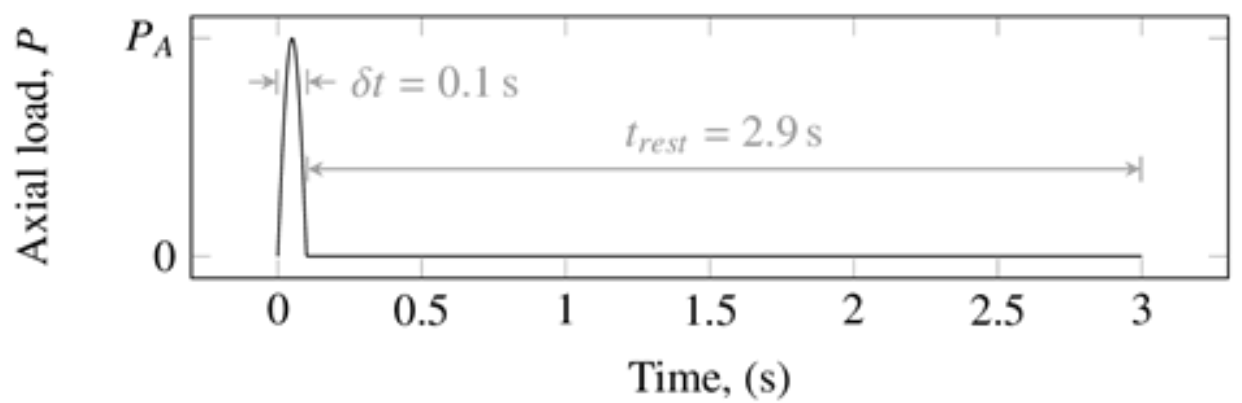




\subsection{Explicit analysis duration}

258 Following the application of the impulse load in the explicit analysis, a rest period is required

259 to allow elastic vibrations in the member to dissipate so that the inelastic deformations could 260 be determined. A suitable rest period has been determined by comparing the analysis results 261 using periods of $1 \mathrm{~s}, 2 \mathrm{~s}, 3 \mathrm{~s}, 5 \mathrm{~s}$ and $10 \mathrm{~s}$. It was found that for a duration equal to or greater 262 than $3 \mathrm{~s}$, any elastic deformations imposed on the damaged upright model had negligible effects 263 on the upright's residual capacity. In order to ensure that only permanent (inelastic) 264 deformations are imposed on the damaged upright model, the impulse load shown in Figure 12 265 is used in the present analysis.

\subsection{Critical impulse amplitude}

267 The critical impulse amplitude $P_{A c r}$ is defined as the amplitude that results in a residual capacity $268 P_{u r}$ equal to $95 \%$ of the undamaged static ultimate capacity $P_{u}$. If the residual capacity of the 269 upright is lower than $95 \%$, the upright is considered to have a significant capacity reduction. In 270 the present study, each member was analysed using a range of impulse ratios from $P_{A} / P_{u}=$ $271\{1.00,1.05,1.10 \ldots\}$ until the critical amplitude was reached.

272 The geometric and material nonlinear analysis results for all impulses of the $1400 \mathrm{~mm}$ 90-20-L upright 273 are shown in Figure 13 as an example. The critical impulse ratio, $P_{A c r} / P_{u}=1.27$, was determined by 274 linear interpolation. It should be noted that any residual capacity found to be greater than the static 275 ultimate capacity $P_{u}$ was taken as equal to $P_{u}$.

276

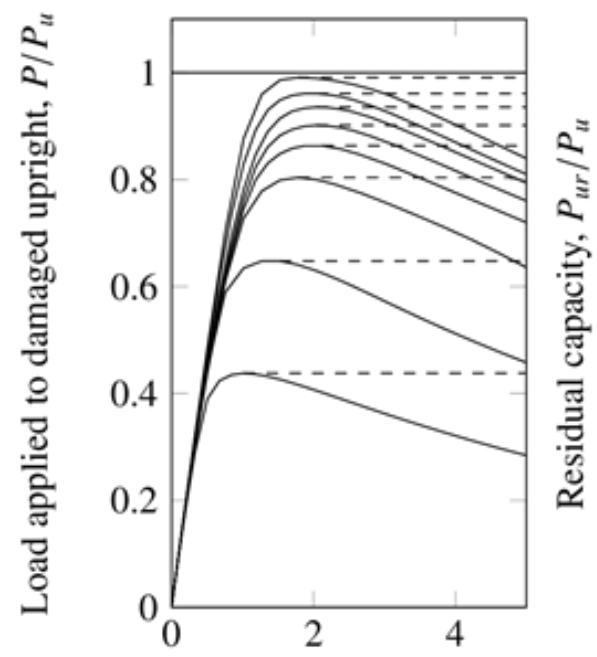

Displacement, (mm)

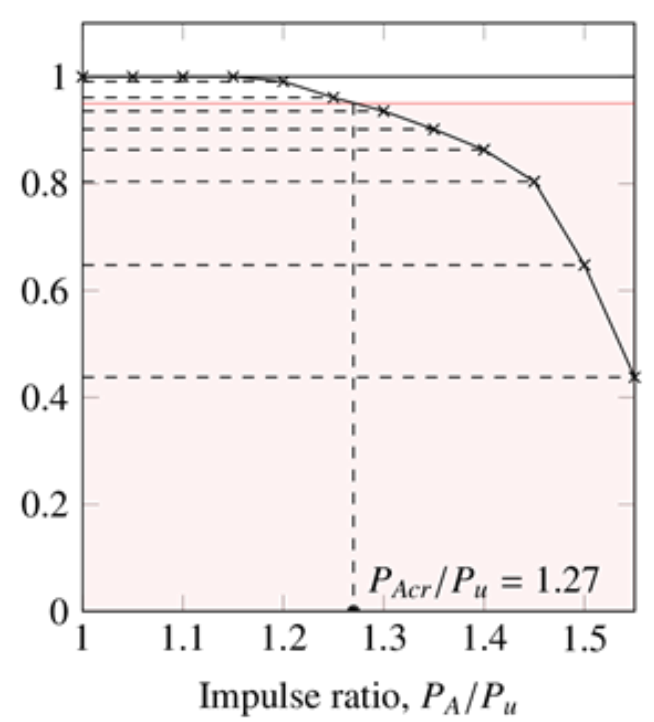

Figure 13: Residual capacities and critical impulse ratio of 1400mm 90-20-L upright 


\subsection{Effect of upright length (with X-bracing)}

279 The effect of upright length on the critical impulse ratio $P_{A c r} / P_{u}$ was determined by analysis of 280 each upright length, given in Figure 11, for each upright section. The results plotted in Figure 281 14(a) show a general increase in the critical impulse ratio with increasing upright length.

282 Damage caused by the critical impulse load typically manifested as local and distortional 283 deformations as seen in Figure 15. When subjected to the nonlinear static analysis to determine 284 the residual capacity, the shorter $1000 \mathrm{~mm}$ and $1400 \mathrm{~mm}$ members failed in local-distortional 285 buckling modes as shown in Figures 16(a) and 16(b). On the other hand, the $1700 \mathrm{~mm}$ and $2862000 \mathrm{~mm}$ uprights failed in flexural-torsional buckling as evident in Figures 16(c) and 16(d). 287 The shorter uprights are therefore more vulnerable to stomping damage. An exception was 288 found for the $1700 \mathrm{~mm} 90-25-\mathrm{H}$ member for which the impulse caused primarily flexural289 torsional deformation, as show in Figure 15(c).

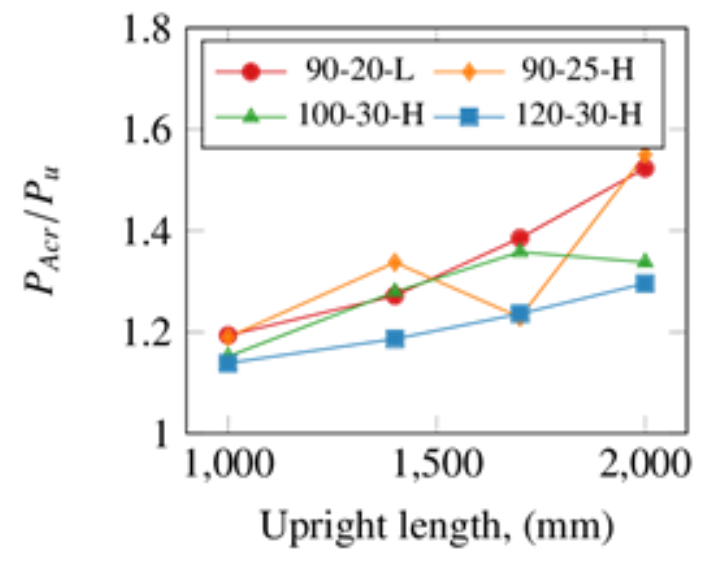

(a)

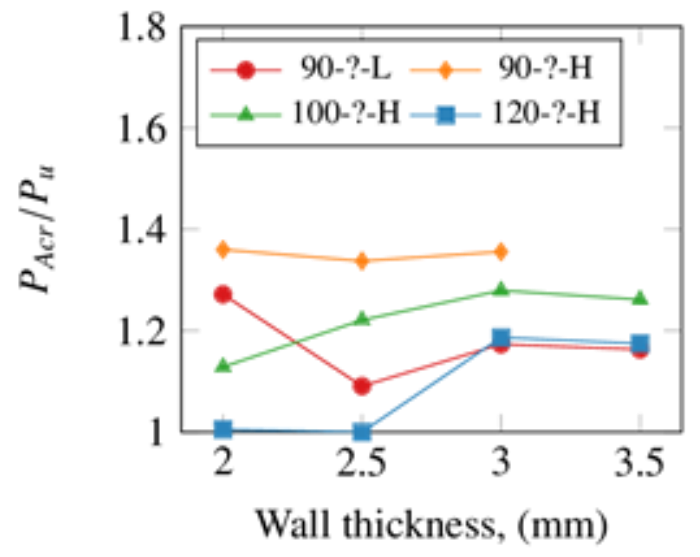

(c)

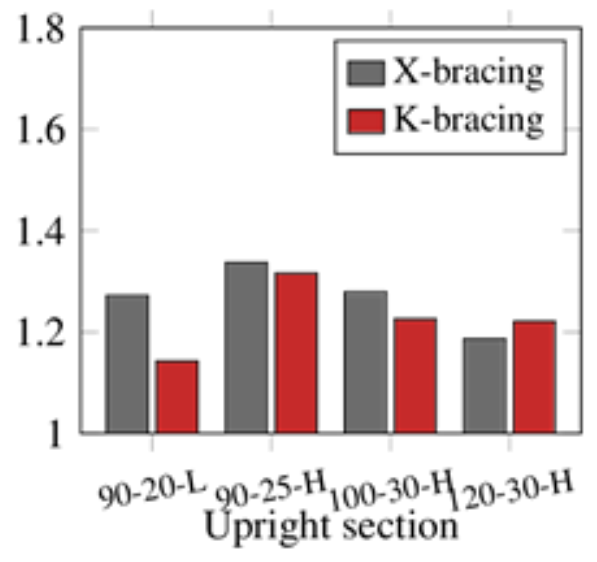

(b)

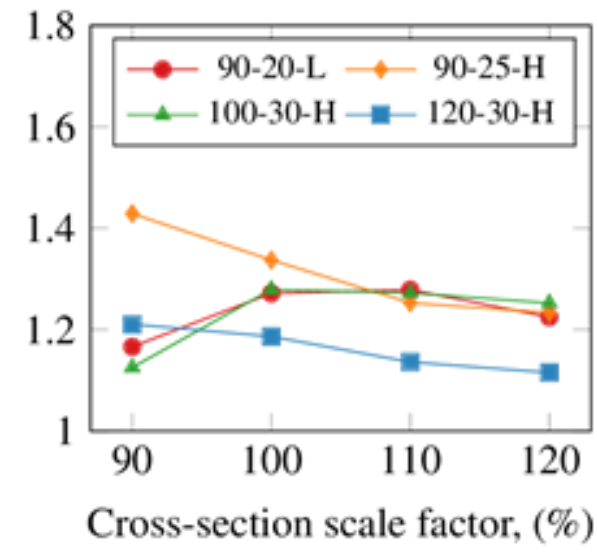

(d) 


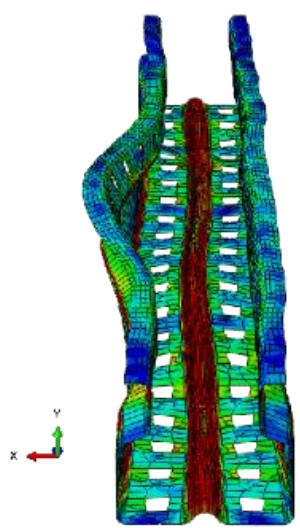

(a) $1000 \mathrm{~mm}$

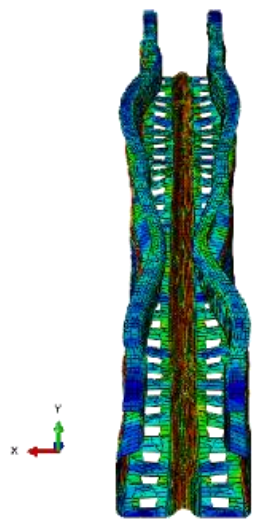

(b) $1400 \mathrm{~mm}$

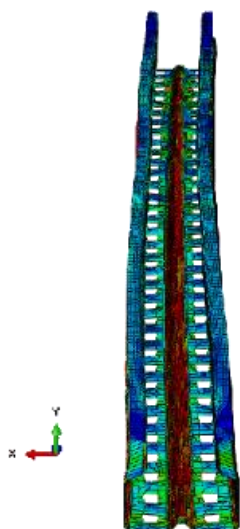

(c) $1700 \mathrm{~mm}$

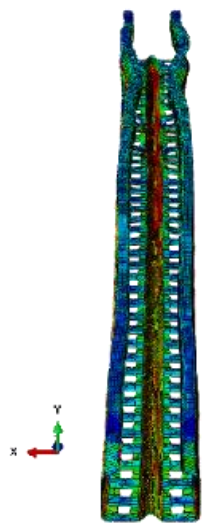

(d) $2000 \mathrm{~mm}$

Figure 15: 90-25-H damaged shape after critical impulse, 10× deformation scaling

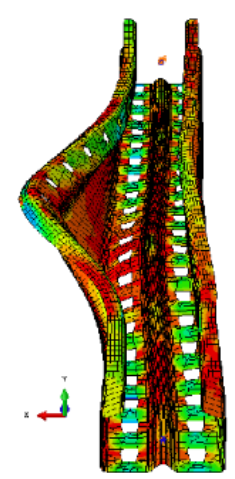

(a) $1000 \mathrm{~mm}$

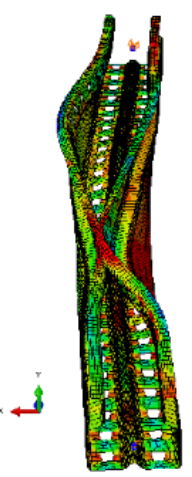

(b) $1400 \mathrm{~mm}$

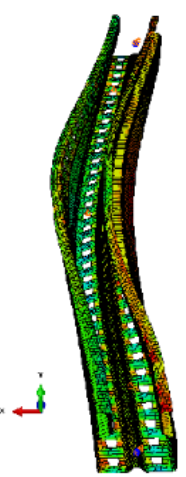

(c) $1700 \mathrm{~mm}$

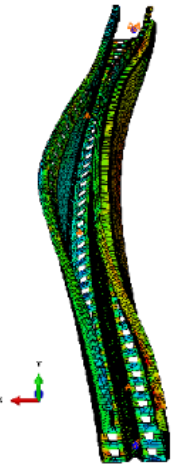

(d) $2000 \mathrm{~mm}$

Figure 16: 90-25-H deformed shapes at critical residual capacity, 10× deformation scaling

\subsection{Effect of bracing pitch (1400 mm upright)}

295 Using the X-bracing rather than the K-bracing configuration was found to increase the critical 296 impulse ratio for the 90-20-L, 90-25-H and 100-30-H upright sections, as shown in Figure 297 14(b). The smaller pitch of the X-bracing configuration tends to ameliorate the damage incurred 298 by the stomping, which largely manifests in the form of local-distortional imperfections for the $2991400 \mathrm{~mm}$ uprights. Local-distortional imperfections are prevented at bracing points.

\subsection{Effect of section slenderness (X-braced $1400 \mathrm{~mm}$ upright)}

301 Up to $3.0 \mathrm{~mm}$, increasing the section thickness was found to mostly increase the critical impulse 302 ratio, as shown in Figure 14(c). As the thickness increased to $3.0 \mathrm{~mm}$, the upright failure mode changed from a local-distortional buckling dominated one to a member buckling dominated 
one, and the upright was therefore less susceptible to the local-distortional damage incurred 305 during stomping.

306 The cross-section scaling study showed that decreasing the member slenderness (by increasing 307 the cross-section scale factor) mostly led to decreasing critical impulse ratios, as shown in 308 Figure 14(d). This outcome is consistent with all the preceding parametric results. It is noted, 309 however, that the 90-20-L and 100-30-H uprights do not follow this trend between cross-section 310 scale factors of $90 \%$ and $100 \%$. It was found that the failure mode of each of these uprights at $31190 \%$ cross-section scaling was different from the common mode at the other scaling factors, as 312 shown in Figure 17.

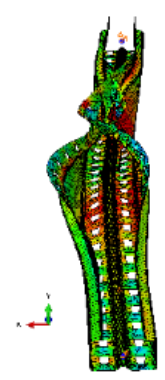

(a) $90-20-\mathrm{L}, 90 \%$

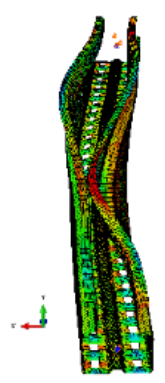

(e) $100-30-\mathrm{H}, 90 \%$

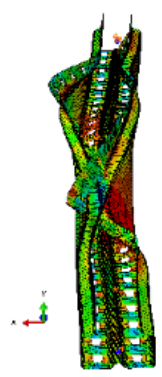

(b) $90-20-\mathrm{L}, 100 \%$

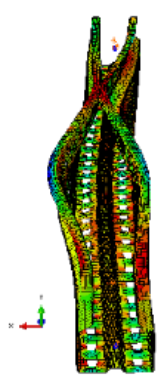

(f) $100-30-\mathrm{H}, 100 \%$

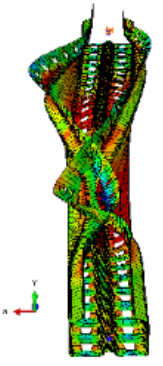

(c) $90-20-\mathrm{L}, 110 \%$

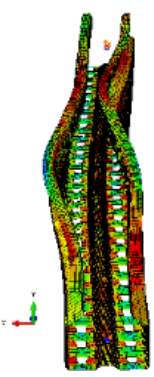

(g) $100-30-\mathrm{H}, 110 \%$

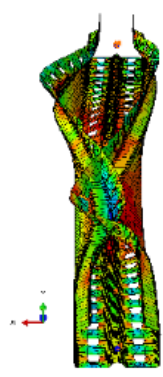

(d) $90-20-\mathrm{L}, 120 \%$

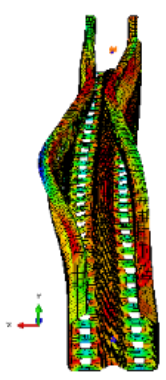

(h) $100-30-\mathrm{H}, 120 \%$

Figure 17: Failure modes of damaged upright members with different cross-section scale factors

\subsection{Bracing torsional restraint}

315 Although torsional restraint at the bracing connection was not provided to the simulated

316 uprights presented in the preceding sections, some bracing details in practice do provide partial 317 torsional restraint. A subset of the previous models were re-analysed with full torsional restraint 318 at each bracing point to gauge the effect of partial torsional restraint. Results of the simulations with and without torsional restraint at the bracing connections are compared in Figure 18. 
320 The models with full torsional restraint at the bracing connections tend to have lower critical 321 impulse ratios than the comparable models with torsional restraints only at the member ends.

322 Torsional restraints had a negligible effect on the $1000 \mathrm{~mm}$ uprights, which had the two bracing 323 connections close to the member ends. In general, the lack of torsional restraints tends to 324 increase the critical impulse ratio as it facilitates the flexural-torsional buckling mode, which is 325 hardly affected by the local-distortional damage incurred by stomping.

326 Furthermore, even for long uprights failing by member buckling rather than cross-section 327 buckling, the absence of torsional restraint can change the buckling mode from flexural to

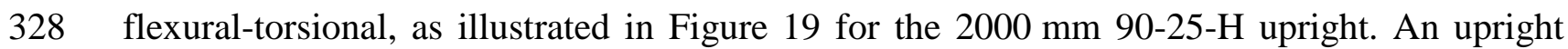
329 failing in the flexural mode is more susceptible to stomping damage than that failing in the 330 flexural-torsional mode, since stomping damage is unlikely to manifest in permanent sweep 331 (torsional deformation).

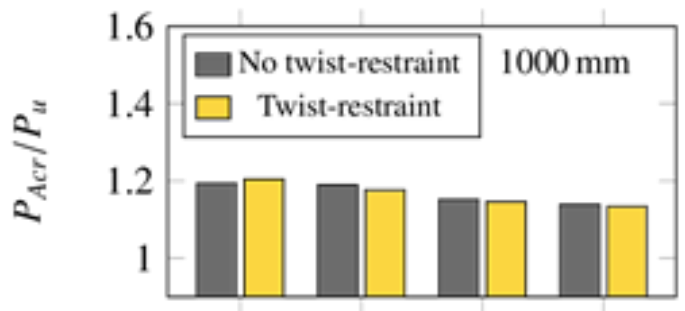

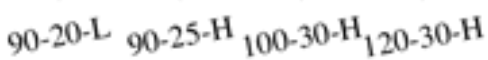

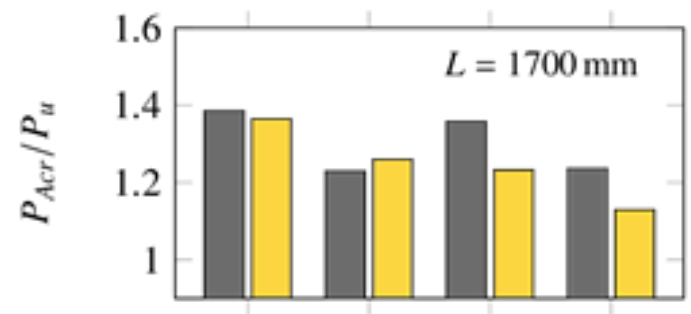

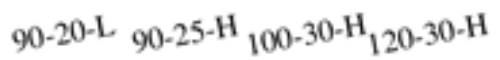

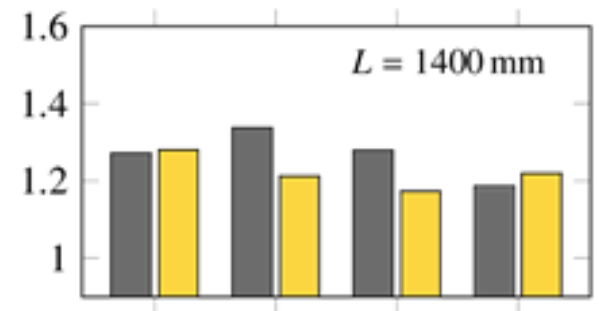

$90-20-\mathrm{L} 90-25-\mathrm{H}_{100-30-\mathrm{H}_{120-30-H}}$

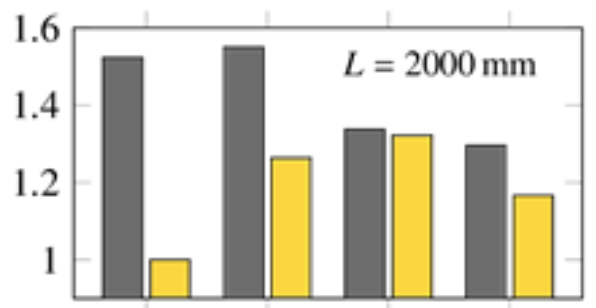

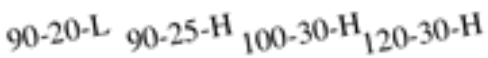

Figure 18: Critical impulse ratios of uprights with and without torsional restraint at bracing 


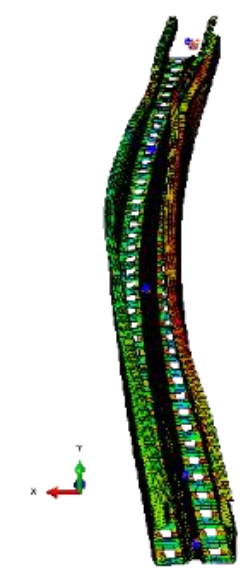

(a) Torsional restraint

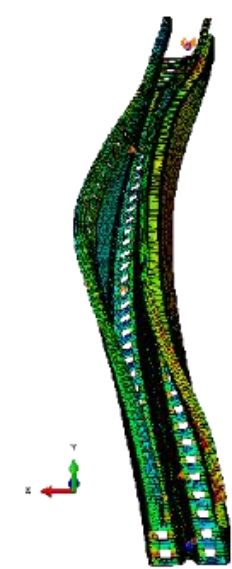

(b) No torsional restraint
Figure 19: Failure modes of damaged 2000mm 90-25-H members with and without torsional restraint at bracing connections

It should be noted that a lower critical impulse ratio does not imply a reduction in the critical impulse amplitude. For example, the presence of full torsional restraints at the bracing points

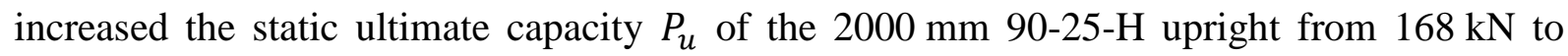
$210 \mathrm{kN}$, and the critical impulse amplitude $P_{A c r}$ from $261 \mathrm{kN}$ to $265 \mathrm{kN}$.

\subsection{Multiple consecutive impulses}

When subjected to multiple consecutive impulses of a given amplitude in the first series (see Section 3.5), the residual capacity of the $1400 \mathrm{~mm}$ uprights often drastically decreased after each consecutive impulse, as shown in Figure 20. The 90-25-H and 100-30-H uprights failed $\left(P_{u r} / P_{u}<0.95\right)$ after two consecutive impulses of amplitude $P_{A} / P_{u}=1.0$ only. The $90-20-\mathrm{L}$ and 120-30-H uprights withstood two consecutive impulses up to $P_{A} / P_{u}=1.10$, and three impulses up to $P_{A} / P_{u}=1.05$. However, it can be seen that the residual capacity quickly decreased after each consecutive impulse of equal magnitude, especially at higher amplitudes. 

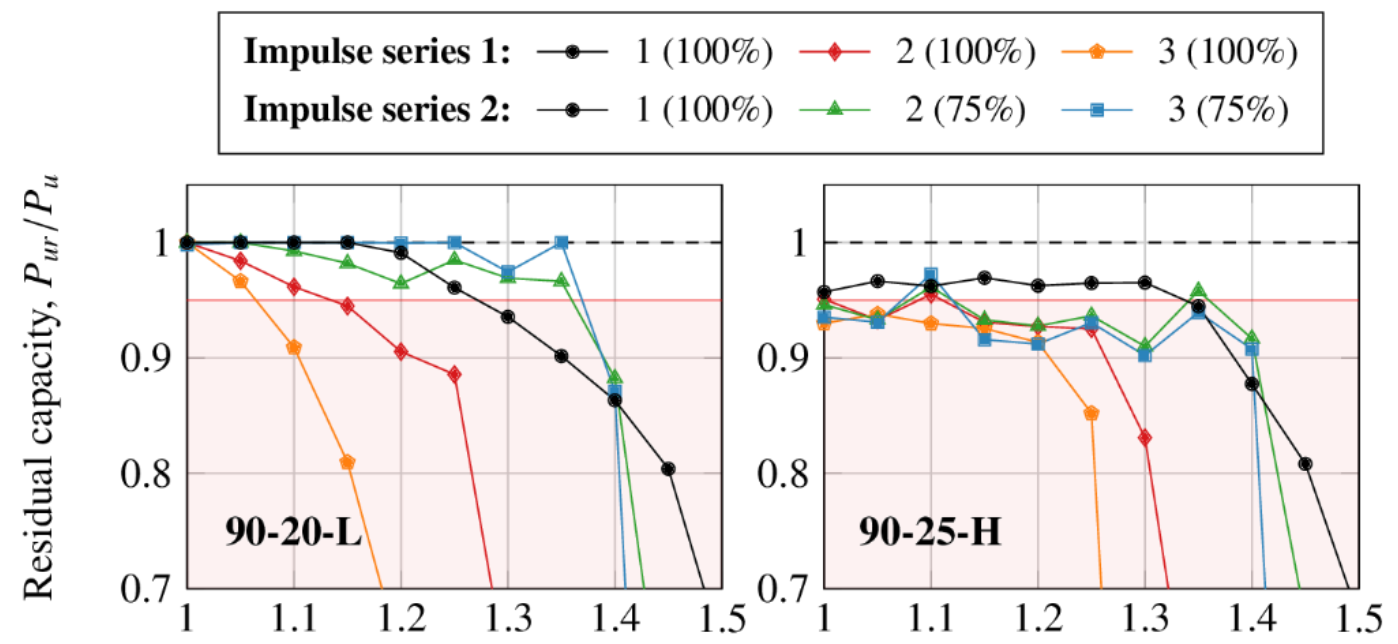

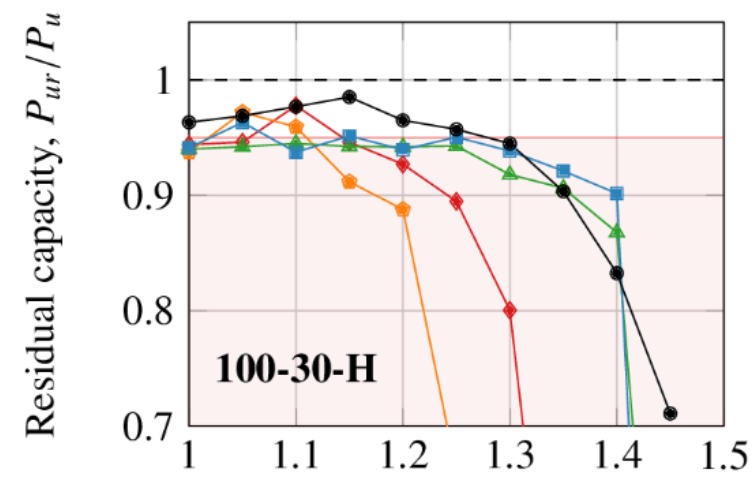

First pulse amplitude, $P_{A} / P_{u}$

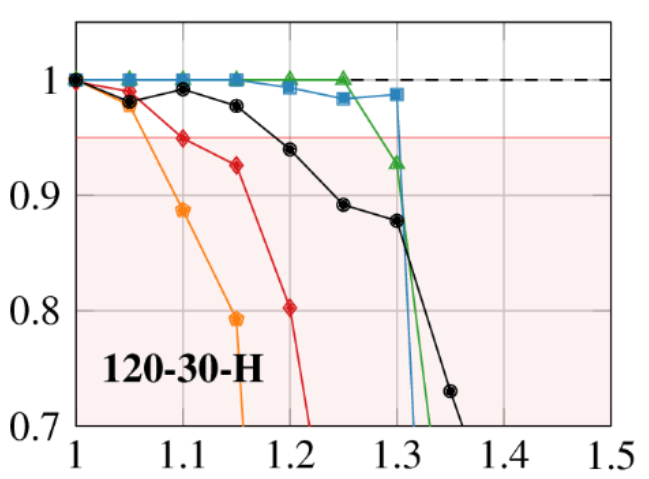

First pulse amplitude, $P_{A} / P_{u}$

349 For the second series, where the second and third impulses were reduced to $75 \%$ of the first,

350 the residual capacity was not consistently decreased by subsequent impulses as in the first

351 series. In any case, it can be seen from Figure 20 that in the more realistic condition encountered

352 during real earthquakes, only the peak impulse is relevant for determining the residual capacity

353 of an upright. This outcome justifies the analysis procedure described in Section 4.1, which was

354 used to generate the results presented in the preceding sections.

\section{Conclusions}

356 The paper has presented an extensive parametric study concerning the effects of stomping forces on the residual capacity of a cold-formed steel rack upright. The shell element analyses found that critical stomping of a rack upright causes damage mostly in the form of inelastic cross-sectional deformations. Damage in the form of inelastic flexural-torsional deformations may prevail only in relatively rare cases. 
Therefore, cold-formed steel rack uprights that fail in the flexural-torsional mode tend to survive higher impulse amplitudes (relative to their static ultimate capacity) than those failing in the local-distortional mode. Adding a return flange to the section, increasing the member effective length, and/or increasing the wall thickness improve the upright's resilience against stomping forces during rocking in an earthquake.

While bracing-to-upright connection detailing that provides torsional restraint increases the upright's static ultimate capacity by a relatively small amount, it can reduce the critical impulse ratio significantly as it leads to more permanent deformations. Bracing detailing that provides low torsional restraint to the upright can increase the upright's resilience against stomping forces during rocking in an earthquake without significantly reducing the static ultimate capacity.

It has been found that, among the 59 upright models analysed, only 9 had a critical impulse ratio $\left(P_{A c r} / P_{u}\right)$ less than 1.15 . Even so, eight of the nine uprights with critical impulse ratios less than 1.15 had their cross-sections modified from actual uprights used in the racking industry by either cross-section scaling or altering thickness; with the ninth being the $2000 \mathrm{~mm}$ 90-20-L member with full torsional restraint applied at the bracing points. Overall, the average critical impulse ratio was 1.23 . It can therefore be surmised that the majority of practical uprights will survive stomping magnitudes at least $15 \%$ greater than their respective static ultimate capacity and retain $95 \%$ or more of their undamaged capacity.

When a cold-formed steel rack upright is subjected to consecutive impulses each of a magnitude equal to the critical impulse magnitude, its residual capacity degrades successively. However, in most earthquakes the maximum stomping forces following the most severe (peak) stomping are only up to $75 \%$ of the peak amplitude. If the peak stomping force in an earthquake is equal to or less than 1.15 times the static ultimate capacity, then subsequent stomping will not likely cause further significant permanent deformations.

A practical implication is that, leaving aside the condition and original capacity of the other rack components, during the post-earthquake emergency period an unanchored storage rack upright that survives through rocking may be able to carry a storage load that is double what it sustains just prior to the earthquake. As one side of the upright frame lifts from the base during rocking, the compressed upright carries all the storage load that is normally shared between the pair of uprights, for a duration of a few seconds or so. This condition means that the upright's 
392

393

394

395

396

397

398

399

400

401

402

403

404

405

406

407

408

409

410

411

412

413

414

415

416

417

418

419

420

static ultimate (axial) capacity must be at least double its compression force under the storage load just prior to the earthquake. If the amplitude of the peak impulse is not more than 2.3 times the compression force under the storage load, then the upright's residual capacity will not be compromised significantly.

The present finite element analysis results can be used to plan the experimental program for optimising the configurations of cold-formed steel storage racks that are designed to rock during earthquake.

\section{Acknowledgements}

This research has been conducted with the support of the Australian Government Research Training Program Scholarship and QuakeCoRE, a New Zealand Tertiary Education Commission-funded Centre. Pallet racking materials were donated for testing by Dexion New Zealand Ltd.

\section{References}

ABAQUS. 2014. ABAQUS/CAE 6.14-2. Dassault Systèmes.

Azuhata, T., Ishihara, T., \& Midorikawa, M. 2007. Effect of impulsive force on earthquake response of rocking structural systems. Pages 459-468 of: WIT Transactions on The Built Environment, vol. I. WIT Press.

Chen, H., \& Liew, J. Y. 2005. Explosion and fire analysis of steel frames using mixed element approach. Journal of Engineering Mechanics, 131(6), 606-616.

Cowper, G. R., \& Symonds, P. S. 1957. Strain-hardening and strain-rate effects in the impact loading of cantilever beams. Tech. rept. Brown University Providence RI.

DOD. 2008. Unified Facilities Criteria (UFC): Structures to resist the effects of accidental explosions, UFC 3-340-02. Design Guide. Department of Defense.

Gilsanz, R., Hamburger, R., Barker, D., Smith, J. L., \& Rahimian, A. 2013. Steel Design Guide 26: Design of blast resistant structures. American Institute of Steel Construction.

Koen, D. 2008. Structural capacity of light gauge steel storage rack uprights. Ph.D. thesis, University of Sydney.

Maguire, J. R. 2019. Behaviour of cold-formed steel selective storage racks subject to rocking. draft Ph.D. thesis, University of Wollongong and University of Auckland. 
Maguire, J. R., Tang, Z., Clifton, G. C., Teh, L. H., \& Lim, J. B. P. 2018a. Shaking table tests of full-scale rocking selective pallet racks. In: QuakeCoRE 2018 Annual Meeting Poster Session.

Maguire, J. R., Teh, L. H., Lee, C. L., Clifton, G. C., \& Lim, J. P. B. 2018b. Three-dimensional simulation of the dynamic rocking response of a cold-formed steel pallet rack. In: 2018 NZSEE Conference Papers.

Makris, N., \& Zhang, J. 1999. Rocking response and overturning of anchored equipment under seismic excitations. PEER Report 1999/06. Pacific Earthquake Engineering Research Center.

Mamalis, A. G., Johnson, W., \& Viegelahn, G. L. 1984. The crumpling of steel thin-walled tubes and frusta under axial compression at elevated strain-rates: Some experimental results. International Journal of Mechanical Sciences, 26 (11), 537-547.

Priestley, M. J. N., Evison, R. J., \& Carr, A. J. 1978. Seismic response of structures free to rock on their foundations. Bulletin of the New Zealand National Society for Earthquake Engineering, 11(3), 141-150.

Riks, E. 1979. An incremental approach to the solution of snapping and buckling problems. International Journal of Solids and Structures, 15(7), 529-551.

Ritchie, C. B., Gow, M. I., Packer, J. A., \& Heidarpour, A. 2017a. Influence of elevated strain rate on the mechanical properties of hollow structural sections. International Journal of Protective Structures, 8(3), 325-351.

Ritchie, C. B., Packer, J. A., Zhao, X. L., Heidarpour, A., \& Chen, Y. 2017b. Dynamic material performance of cold-formed steel hollow sections: A state-of-the-art review. Frontiers of Structural and Civil Engineering, 11(2), 209-227.

Standards Australia. 2011. Continuous hot-dip metallic coated steel sheet and strip - Coatings of zinc and zinc alloyed with aluminium and magnesium, AS 1397-2011, Standards Australia, Sydney.

Standards Australia. 2012. Steel storage racking, AS 4084:2012. Standard. AS/NZS.

Standards New Zealand. 2004. Structural design actions, Part 5: Earthquake actions - New Zealand, NZS 1170.5:2004. Standard. NZS.

Wiebe, L., Christopoulos, C., Tremblay, R., \& Leclerc, M. 2013. Mechanisms to limit higher mode effects in a controlled rocking steel frame. 2: Large-amplitude shake table testing. Earthquake Engineering \& Structural Dynamics, 42(7), 1069-1086. 